\title{
Drug yield and essential oil and carvacrol contents of two species of Satureja (S. khuzistanica Jamzad and S. rechingeri Jamzad) cultivated in two different locations
}

\author{
Ahmad Nooshkam a , Hasan Mumivand ${ }^{\text {b,* }}$, Javad Hadian ${ }^{\text {c }}$, Ali Alemardan ${ }^{\mathrm{d}}$, Mohammad Reza \\ Morshedloo $^{\mathrm{e}}$ \\ ${ }^{a}$ Department of Agronomy, Faculty of Agricultural Science and Engineering, College of Agriculture and \\ Natural Resources, University of Tehran, Karaj 31587, Iran \\ ${ }^{b}$ Department of Horticultural Sciences, Faculty of Agriculture, Lorestan University, PO Box 465, \\ Korramabad, Iran
}

${ }^{c}$ Medicinal Plants and Drug Research Institute, Shahid Beheshti University, G. C., Evin, Tehran, 1983963113, Iran

d Department of Horticultural Science, Faculty of Agricultural Science and Engineering, College of Agriculture and Natural Resources, University of Tehran, Karaj 31587, Iran

${ }^{\mathrm{e}}$ Department of Horticultural Science, Faculty of Agriculture, University of Maragheh, Maragheh, Iran

*Corresponding author Fax: +9806633400012

E-mail address: hmumivand@ gmail.com: hmumivand@ut.ac.ir 


\begin{abstract}
Satureja khuzistanica and Satureja rechingeri are two valuable medicinal perennial species endemic to Iran. They grow wild in southwest parts of Iran. These species are rich in carvacrol, with considerable biological activities. In order to study the effects of climate and region conditions on plant height, leaves + flowering shoots yield (drug yield), essential oil content and yield, and carvacrol content, two years field experiments were conducted in two different locations (Andimeshk and Kashkan) in Iran during 2012 and 2013. The result showed that (average of both years) drug yield of either species in Kashkan (2.6 t ha-1) was higher than in Andimeshk (1.05 $\left.\mathrm{t} \mathrm{ha}^{-1}\right)$. Drug yield of $S$. khuzistanica $\left(1.9 \mathrm{t} \mathrm{ha}^{-1}\right)$ in either region was higher than that of $S$. rechingeri $\left(1.7 \mathrm{t} \mathrm{ha}^{-1}\right)$. S. reshingeri $(37.6 \pm 3.5 \mathrm{~cm})$ was shorter than $S$. khuzistanica $(40.5 \mathrm{~cm})$ in either location. In Kashkan, the species grew taller $(40.9 \mathrm{~cm})$ than in Andimeshk $(37.3 \mathrm{~cm})$. In addition, essential oil content of S. rechingeri $(4.5 \%)$ in both regions was more than that of S. khuzistanica (1.9\%). Essential oil content of both species in Andimeshk (3.3\%) was more than in Kashkan (3.1\%). Essential oil yield obtained from S. reshigeri $(77.3 \mathrm{~kg}$ $\mathrm{ha}^{-1}$ ) was higher than that from S. khuzistanica due to its higher essential oil content. However, neither location nor species significantly affected carvacrol content. Carvacrol was the main component of the essential oil (95.9-96.7\%). Overall, the results showed that both species performed better in the cooler region (Kashkan) but with a higher essential oil content in the warmer region (Andimeshk).
\end{abstract}

Keywords: Carvacrol, Essential oil, Drug yield, Satureja khuzistanica, Satureja rechingeri

\title{
1. Introduction
}

The genus Satureja, belonging to the Lamiaceae family and the Nepetoideae subfamily, consists of 30 species. It is mainly distributed in the Mediterranean areas. 14 species of Satureja are growing wild in northern, northwestern, western, southwestern, and central parts of Iran (Jamzad, 1994), nine of which (S. khuzistanica Jamzad, S. rechingeri Jamzad, S. bakhtiarica bunge, S. atropatana, S. edmondi, S. isophylla, S. kallarica jamzad, S. sahendica, and $S$. macrosiphonia) are endemic to Iran. S. khuzistanica and S. rechingeri, as perennial plants, are widely distributed in the southwestern parts of Iran (Jamzad, 2009). High similarities have been observed between $S$. rechingeri and S. khuzistanica regarding morphological characteristics and essential oil composition. S. khuzistanica and S. reshingeri are popular herbs for the local 
population, being used as herbal tea and for their therapeutic virtues as analgesic and antiseptic medicines in the traditional medicine. Recently, many diverse activities (e.g. antifungal, antibacterial, antinociceptive, antioxidant, antidiabetic, antihyperlipidemic, antibiofilm, antiinflammatory, and triglyceride-lowering activities) have also been observed in $S$. khuzistanica and S. reshingeri (Hadian et al., 2011). The composition of S. khuzistanica and $S$. reshingeri essential oils have been reported previously. The main components of the essential oil of S. khuzistanica were carvacrol (48\%), p-cymene (18.5\%), and $\gamma$-terpinene (11\%) (Farzaneh et al., 2015), and carvacrol (80-95.4\%) (Farsam et al., 2004; Hadian et al., 2011). Similarly, carvacrol $(86.6 \%)$ and $p$-cymene $(2.4 \%)$ were the main components of the essential oil of $S$. reshingeri (Sefidkon et al., 2007). Carvacrol has also been reported as the major component of the essential oils of other Satureja species (S. boissieri, S. mutica, and S. hortensis), but its content was lower than $40 \%$ (Sefidkon, 2007). The comparison of the essential oils of $S$. khuzistanica and S. reshingeri with those of other Satureja species indicates that the highest percentage of carvacrol exists in these two species. Carvacrol seems to be responsible for the biological activities of these species.

S. khuzistanica and S. reshingeri are valuable herbs used in pharmaceutical and food industries due to their pharmacological and biological properties. Herbal drops of the species are used as dental anesthetic and oral antiseptic drugs (Hadian et al., 2011). Nowadays, herbal drugs of these endemic plants are collected from wild niches to meet the demands of the pharmaceutical and food industries. The degradation of genetic diversity, the extinction of ecotypes, and the unreliable supply of herbaceous materials are the main challenges facing wild collection. To solve these problems, the emphasis is placed on domestication and cultivation, which contribute to germplasm conservation and an ensured supply of herbal raw material.

Growth and essential oil composition of plants in natural conditions or agro-ecosystems can be affected by many factors, categorized into internal (genetic constitution and age or development stage) and external factors (soil properties, moisture, temperature, day length, light quality, nutrient levels, and wind patterns) (Carrubba and Catalano, 2009). Both categories have extremely variable effects on the plant growth, yield, quantity, and quality of the essential oil. The effects of ecological conditions on (1) Cunila galioide in Brazil (Echeverrigaray et al., 2003), (2) Thymus sp. in southeast Spain (Horwath et al., 2008), (3) Lavandula latifolia in Spain (Munoz et al., 2007), (4) Salvia officinalis L. in south-central Italy (Russo et al., 2013), (5) 
Thymus daenensis Celak and Thymus vulgaris L. in central Iran (Ghasemi Pirbalouti et al., 2013), and (6) Mentha piperita L. in Turkey (Telci et al., 2011) have been studied and the results indicate that the yield, quantity, and quality of the essential oils were affected by ecological factors (due to the different soil and climatic conditions). Therefore, determining the effects of different ecological conditions on cultivated plants is important to produce a high quality crop. The objective of the present study was to investigate the effects of different ecological conditions on yield, essential oil production, and carvacrol content of two valuable endemic medicinal species: S. khuzistanica and S. rechingeri. For this purpose, S. khuzistanica and S. rechingeri were cultivated in two different regions in Iran (Andimeshk and Kashakn).

\section{Material and methods}

\subsection{Plant material and field experiments}

Two two-year field trials, arranged in randomized complete block designs, each with six replications per treatment, were conducted in two locations in Iran: (1) Edrisi sofla village, Andimeshk, Khuzestan $\left(32.45^{\circ} \mathrm{N}, 48.35^{\circ} \mathrm{E}\right)$ and (2) Kashkan bridge, Lorestan $\left(33.98^{\circ} \mathrm{N}, 51.41^{\circ}\right.$ E) during 2012-2013. The geographical positions, soil properties, and some climatic data of the locations are presented in Tables 1 and 2, respectively.

"insert Table 1 and Table 2"

The two species (S. reshingeri and S. khuzistanica) were identified by the Department of Botany of the Research Institute of Forests and Rangelands (TARI), Tehran, Iran. Voucher specimens of the two species (No. 58416 for S. khuzestanica and No. 75587 for S. reshingeri) have been deposited at the Herbarium of TARI. Healthy cuttings of the two species were used as propagules. 8-10 cm cuttings were taken from a mother plantation of S. khuzistanica grown at the Khorraman Pharmaceutical Company field (Khorramabad, Lorestan) on 27 December 2011. For S. reshingeri, cuttings were taken from a natural habitat (Mehran region in Ilam province) on 31 December 2011. Cuttings were planted in small pots and grown in a greenhouse for 135 days before being transplanted in the experimental field. Small plants of the two species were transplanted $50 \mathrm{~cm} \times 50 \mathrm{~cm}$ apart in the field on 4 May 2012. Each plot was sized $2 \mathrm{~m} \times 4 \mathrm{~m}$ and contained 4 rows. The average density was 4 plants per $\mathrm{m}^{2}$. At the early growth stage, the plants were watered once a week for better plant establishment, and then at 15-day intervals. Weeds were controlled by hand-hoeing when necessary. No fertilizer (organic or inorganic) or pesticide 
was used during the experiment. Since S. khuzistanica and S. rechingeri are perennial plants, the data of the second year were obtained from the same plants, which regrew. After full flowering stage, five plants were selected from the middle of each plot, and plant heights were measured. The aerial parts of the species (four plants in $1 \mathrm{~m}^{2}$ ) were harvested in each region at full flowering stage in September and October either in 2012 or in 2013 (The harvest was done at the same date in both years) by cutting five plants approximately $10 \mathrm{~cm}$ above the ground (Table 3). The herbage was air-dried in the shade at room temperature (Karamanos and Sotiropoulou, 2013; Teles et al., 2013). The leaves and flowering shoots (oil bearing parts of the plant) were separated from the dried woody stems, weighed, and recorded as the drug yield. "insert Table 3"

\subsection{Essential oil isolation}

After the leaves and flowering shoots were ground into a fine powder, the essential oil was isolated via hydro-distillation, using a Clevenger-type apparatus (30 g sample were mixed into $300 \mathrm{~mL}$ distilled water), with a distillation time being approximately $3 \mathrm{~h}$ at boiling point. The oils extracted were dried with anhydrous sodium sulfate $\left(\mathrm{Na}_{2} \mathrm{SO}_{4}\right)$, and then stored in tightly closed, dark vials at $4{ }^{\circ} \mathrm{C}$ until analysis. The volume of the essential oil produced was measured and

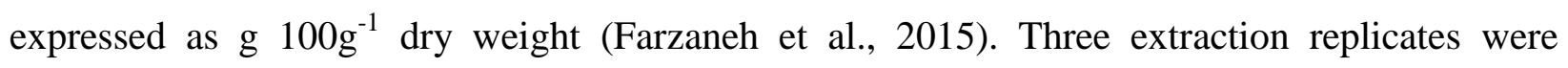
prepared for each treatment.

\subsection{Gas chromatography and compound identification}

The GC-FID analysis of the oils was conducted using a Thermoquest-Finnigan apparatus equipped with a flame ionization detector (FID) and a DB-5 fused-silica capillary column (30 m $\times 0.25 \mathrm{~mm}$ i.d., film thickness $0.25 \mathrm{~mm}$ ). The oven temperature was programmed from 60 to 250

${ }^{\circ} \mathrm{C}$ at $4{ }^{\circ} \mathrm{C} \mathrm{min}{ }^{-1}$ and held isothermal at $250{ }^{\circ} \mathrm{C}$ for $10 \mathrm{~min}$; injector temperature $250{ }^{\circ} \mathrm{C}$; detector temperature $300{ }^{\circ} \mathrm{C}$; carrier gas $\mathrm{N}_{2}\left(1.1 \mathrm{ml} \mathrm{min}^{-1}\right)$; split ratio 1:50. Quantitative data was obtained from GC-FID area percentages without the use of correction factors (Hadian et al., 2011). Each sample and standard was injected three times.

The GC/MS analysis was conducted with a Thermoquest-Finnigan Trace apparatus equipped with a DB-5 fused-silica capillary column (60 $\mathrm{m} \times 0.25 \mathrm{~mm}$ i.d., film thickness $0.25 \mathrm{~mm})$. The oven temperature was programmed from 60 to $250{ }^{\circ} \mathrm{C}$ at $4{ }^{\circ} \mathrm{C} \mathrm{min}{ }^{-1}$ and held isothermal at 250 
${ }^{\circ} \mathrm{C}$ for $10 \mathrm{~min}$; ion source and transfer-line temperature $250{ }^{\circ} \mathrm{C}$; carrier gas $\mathrm{He}\left(1.1 \mathrm{ml} \mathrm{min}{ }^{-1}\right)$. The mass spectrum was acquired over the mass range of 35-465 amu with an ionization voltage of $70 \mathrm{eV}$ (Hadian et al., 2011).

The identification of carvacrol was performed by comparing its mass with those of the internal reference mass spectra library (Adamsand Wiley 7.0) or with the authentic compound and confirmed by comparing its retention indices (RI) with the authentic compound or with those reported in the literature (Adams, 2007). Quantification of the relative percentage of carvacrol in the essential oil was performed according to the area percentage method.

\subsection{Statistical analysis}

The mean of data for each variable (plant height, drug yield, essential oil content and yield, and carvacrol content) collected in two years were statistically analyzed by using two-way analysis of variance (ANOVA) based on the GLM procedure of the SAS statistical package (SAS; version 9.1). Significance of the differences between location (L), species (S), and their interactions $(\mathrm{L} \times \mathrm{S})$ for the variables were tested using LSD $(\mathrm{p}<0.05)$. The data of all variables were also shown as mean \pm standard deviation calculated from replications.

\section{Results and discussion}

\subsection{Yield of leaves + flowering shoots (drug yield)}

The results indicated that the effects of species, location, and species $\times$ location on drug yield ( $\mathrm{p}<0.01$ ) were significant (Table 4). The drug yield of $S$. khuzistanica $\left(1.95 \pm 0.93 \mathrm{t} \mathrm{ha}^{-1}\right.$ ) was higher in either region, compared to that of S. reshigeri. The highest drug yield $\left(2.63 \pm 0.4 \mathrm{tha}^{-1}\right)$ was obtained from the plants grown in Kashkan (Table 4). S. khuzistanica cultivated in Kashkan produced the highest drug yield $\left(2.84 \pm 0.31 \mathrm{t} \mathrm{ha}^{-1}\right)$, while S. reshigeri in Andimeshk had the lowest yield $\left(1.04 \pm 0.15 \mathrm{tha}^{-1}\right)$. The differences observed in the two regions can be attributed to climatic differences between the locations, as reported in table 1 and 2 . The mean annual temperature for Andimeshk and Kashkan was $27.2^{\circ} \mathrm{C}$ and $15.9^{\circ} \mathrm{C}$, respectively (Table 1). In addition, the average temperature during the growth period was $32{ }^{\circ} \mathrm{C}$ in Andimeshk and $21{ }^{\circ} \mathrm{C}$ in Kashkan (Table 2). The lower temperature and soil EC, higher soil available P, and better soil texture in Kashkan compared with Andimeshk resulted in a better plant growth and performance. Therefore, the highest yield was obtained from the plants grown in Kashkan (Table 4). Similar 
results were found for Coriandrum sativum L. in Turkey, where plants in an area with a longer growing period produced a higher biomass and seed yield (Telci et al., 2006). In contrast, some studies have reported that the highest biomass yield in Mentha $\times$ piperita L. (Telci et al., 2011) and Thymus vulgaris (Ghasemi Pirbalouti et al., 2013) were obtained in warmer regions. The results of the present study could also be partially related with the soil characteristics (Telci et al., 2011). The reason that the plants had the lowest drug yield in Andimeshk is probably the clay heavy soil of the region (soil texture) and the higher salinity of the soil (Table 1). In heavy and saline soils, plants have to consume more energy for the root growth and the absorption of water and nutrients. These conditions lead to a decrease in plant growth and yield.

\subsection{Plant height}

The results showed that the plant height was affected by both of the environmental conditions (location) and the species. Plant height of S. reshingeri $(37.6 \pm 3.5 \mathrm{~cm})$ was lower than that of $S$. khuzistanica $(40.5 \pm 3.9 \mathrm{~cm})$ in either location. The plant height in Kashkan $(40.9 \pm 4.2 \mathrm{~cm})$ was higher than in Andimeshk (37.3 $\pm 2.7 \mathrm{~cm}$ ) (Table 4). The difference between locations in terms of plant height can be attributed to the different temperature and soil characteristics: EC, texture, available $\mathrm{P}$, etc. (Table 1, 2, 3).

\subsection{Essential oil content}

The production of essential oils in plants is an adaptation strategy to environmental factors. Statistical analysis showed that there were significant differences between the locations $(\mathrm{p}<0.05)$ and species $(\mathrm{p}<0.01)$ in terms of essential oil content. However, the interactive effect of species and location on essential oil content was not significant (Table 4). The essential oil content of $S$. reshingeri $(4.5 \pm 0.28 \%)$ was higher in either region. The differences observed between the species in terms of essential oil content can be attributed to their genetic differences. The highest essential oil content $(3.3 \pm 1.2 \%)$ was obtained from the plants grown in the warmer region (Andimeshk) (Table 4). In general, plants secrete more essential oil in warm conditions, a strategy that protects them against water stress and intense light (Horwath et al., 2008). Our results are in agreement with the results of studies on Origanum vulgare in Greece (Vokou et al., 1993), Coriandrum sativum L. in Turkey (Telci et al., 2011), and Lavandula latifolia in Spain (Munoz et al., 2007). The higher essential oil content in plants cultivated in Andimeshk might also be attributed to the lower altitude. The essential oil content usually increases when a plant is 
grown at a low altitude. Similar results were found for Origanum vulgare (Vokou et al., 1993) and Thymbra spicata var. spicata (Kizil, 2010). On the contrary, Moghaddam and Farhadi (2015) reported that the essential oil content of Ferula assa-foetida L. reduced with increasing altitude and decreasing temperature.

\subsection{Essential oil yield}

The essential oil yield depends on the leaf yield and essential oil content. Species, locations, and species $\times$ location had significant effects $(\mathrm{p}<0.01)$ on the essential oil yield. The essential oil yield obtained from S. reshigeri $\left(77.3 \pm 33.7 \mathrm{~kg} \mathrm{ha}^{-1}\right)$ was higher than that from $S$. khuzistanica due to its high essential oil content $(4.5 \pm 0.28 \%)$. The higher essential oil yield obtained from the cultivation in Kashkan region was due to the drug yield $\left(2.63 \pm 0.4 \mathrm{t} \mathrm{ha}^{-1}\right)$ (Table 4). This can be due to the reasons (the better plant growth in the colder region) mentioned above (section 3.1). The highest essential oil yield $\left(107.97 \pm 16.19 \mathrm{~kg} \mathrm{ha}^{-1}\right)$ was obtained from S. reshingeri cultivated in Kashkan location, whereas S. khuzistanica grown in Andimeshk produced the lowest essential oil yield $\left(23.03 \pm 5.4 \mathrm{~kg} \mathrm{ha}^{-1}\right)$ (Table 4). Despite the higher drug yield of $S$. khuzistanica compared to $S$. reshingeri, the essential oil yield of S. reshingeri was about twice as that of S. khuzistanica in either location.

"insert Table 4"

\subsection{Carvacrol content}

The results revealed that carvacrol, as the main component of the essential oil at a high percentage (95.96-96.77\%), was not significantly affected by the cultivated area in either species. There were no significant differences $(\mathrm{p}<0.05)$ between the two Satureja species cultivated in two regions in terms of carvacrol content (Table 5). Similar results have been reported by other researchers. Hadian et al. (2011) studied the essential oil composition of eight populations of $S$. khuzistanica from different locations of Iran. Their results indicated that all populations had carvacrol as the main component with a very high content (89.59-95.41\%). The maximum and minimum carvacrol content was obtained in the Choveny (95.41\%) and Takhteshan (89.59\%) populations, respectively. In another study on S. khuzistanica, it was shown that geographic, climatology, and edaphic factors had no significant effects on carvacrol content. Furtheremore, carvacrol was found as the principal component $(94.8 \%)$ in the essential oil of all populations (Ghasemi Pirbalouti et al., 2011). Carvacrol has also been reported as the major component of 
the essential oils of other Satureja species (S. boissieri, S. mutica, and S. hortensis), but its content was lower than 40\% (Sefidkon et al., 2007). Carvacrol is a monoterpenoid phenol biosynthesized via aromatization of $\gamma$-terpinene to $p$-cymene and subsequent hydroxylation of $p$ cymene. It plays a significant role in the adaptation of oil-bearing plants to environmental conditions and has a wide range of activities including antimicrobial, antioxidant, anticandidal, and anti-inflammatory (Hadian et al., 2011).

"insert Table 5"

\section{Conclusions}

The drug yield, essential oil content, oil yield, and plant height of the two Satureja species are considerably affected by the geographical region. Neither location nor species had significant effects on the carvacrol content of the two Satureja species studied. Carvacrol was the main component of the essential oil present at a high percentage (95.96-96.77\%) in both species and regions. Both species had higher plant height, yield of leaves + flowering shoots (drug yield), and essential oil yield in the cooler region (Kashkan), but higher essential oil contents in the warmer region (Andimeshk). These differences could be explained by different environmental parameters such as soil and climatic conditions.

\section{Acknowledgments}

The authors acknowledge the support by Department of Agronomy and Plant Breeding, University of Tehran; Department of Agriculture, Medicinal Plants and Drug Research Institute, University of Shahid Beheshti; Department of Soil Biology and Institute of Water and Soil Research of Karaj; and the Khorraman Pharmaceutical Company of Khorramabad.

\section{References}

Adams RP, 2007. Identification of essential oil components by gas chromatography/mass spectrometry, 4th ed. Allured publishing corporation. Illinois, USA, 804 pp.

Carrubba A, Catalano C, 2009. Essential Oil Crops for Sustainable Agriculture-A Review. In: Climate Change, Intercropping, Pest Control and Beneficial Microorganisms. Springer, Netherlands, pp. 137-187. doi: 10.1007/978-90-481-2716-0-8 
Echeverrigaray S, Fracaro F, Dos Santos ACA, Paroul N, Wasum R, Serafini LA, 2003.

Essential oil composition of south Brazilian populations of Cunila galioides and its relation with the geographic distribution. Biochemical Systematics and Ecology, 31, 467475. doi: 10.1016/S0305-1978(02)00175-8

Farsam H, Amanlou M, Radpour MR, Salehinia AN, Shafiee A, 2004. Composition of the essential oils of wild and cultivated Satureja khuzistanica Jamzad from Iran. Flavour Fragrance J, 19, 308-310. doi: 10.1002/ffj.1300

Farzaneh M, Kiani H, Sharifi R, Reisi M, Hadian J, 2015. Chemical composition and antifungal effects of three species of Satureja (S. hortensis, S. spicigera, and S. khuzistanica) essential oils on the main pathogens of strawberry fruit. Postharvest Biology and Technology, 109, 145-151. doi:10.1016/j.postharvbio.2015.06.014

Ghasemi Pirbalouti A, Hashemi M, Ghahfarokhi FT, 2013. Essential oil and chemical compositions of wild and cultivated Thymus daenensis Celak and Thymus vulgaris L. Industrial Crops and Products, 48, 43-48. doi:10.1016/j.indcrop.2013.04.004

Ghasemi Pirbalouti A, Moalem E, Yousefi M, Malekpoor F, Yousef-Naanaie S, 2011. Influence of 315 ecological factors on carvacrol content of Satureja khuzistanica Jamzad. Journal of essential oil-bearing plants, 14, 630-638. doi:10.1080/0972060X.2011.10643982

Hadian J, Mirjalili MH, Kanani, MR, Salehnia, A, Ganjipoor P, 2011. Phytochemical and Morphological Characterization of Satureja khuzistanica Jamzad Populations from Iran. Chemistry \& Biodiversity, 8, 902-915. doi: 10.1002/cbdv.201000249

Horwath AB, Grayer RJ, Keith-Lucas DM, Simmonds MS, 2008. Chemical characterization of wild populations of Thymus from different climatic regions in southeast Spain. Biochemical Systematics and Ecology, 36, 117-133. doi:10.1016/j.bse.2007.08.009

Jamzad Z, 1994. A new species of the genus Satureja (Lamiaceae) from Iran. Iranian journal of botany, 6, 215-218. 
Jamzad Z, 2009. Thymus and Satureja species of Iran, Publications of Research Institute of Forests and Rangelands. Tehran, 171 pp. (in Persian).

Karamanos AJ, Sotiropoulou DE, 2013. Field studies of nitrogen application on Greek oregano (Origanum vulgare hirtum (Link) Ietswaart) essential oil during two cultivation seasons. Industrial Crops and Products, 46, 246-252. doi:10.1016/j.indcrop.2013.01.021

Kizil S, 2010. Determination of essential oil variations of Thymbra spicata var. spicata L. naturally growing in the wild flora of East Mediterranean and Southeastern Anatolia regions of Turkey. Industrial Crops and Products, 32, 593-600. doi:10.1016/j.indcrop.2010.07.008

Moghaddam M, Farhadi N, 2015. Influence of environmental and genetic factors on resin yield, essential oil content and chemical composition of Ferula assa-foetida L. populations. Journal of Applied Research on Medicinal and Aromatic Plants, 2, 69-76. doi:10.1016/j.jarmap.2015.04.001

Munoz-Bertomeu J, Arrillaga I, Segura J, 2007. Essential oil variation within and among natural populations of Lavandula latifolia and its relation to their ecological areas. Biochemical Systematics and Ecology, 35, 479-488. doi:10.1016/j.bse.2007.03.006

Russo A, Formisano C, Rigano D, Senatore F, Delfine S, Cardile V, Bruno M, 2013. Chemical composition and anticancer activity of essential oils of Mediterranean sage (Salvia officinalis L.) grown in different environmental conditions. Food and Chemical Toxicology, 55, 42-47. doi: 10.1016/j.fct.2012.12.036

Sefidkon F, Abbasi K, Jamzad Z, Ahmadi S, 2007. The effect of distillation methods and stage of plant growth on the essential oil content and composition of Satureja rechingeri Jamzad. Food chemistry, 100, 1054-1058. doi:10.1016/j.foodchem.2005.11.016

Telci I, Kacar O, Bayram E, Arabac O, Demirtas I, Yilmaz G, Göksu E, 2011. The effect of ecological conditions on yield and quality traits of selected peppermint (Mentha piperita 
L.) clones. Industrial Crops and Products, 34, 1193-1197. doi:10.1016/j.indcrop.2011.04.010

Telci I, Toncer OG, Sahbaz N, 2006. Yield, essential oil content and composition of Coriandrum sativum varieties (var. vulgare Alef and var. microcarpum DC.) grown in two different locations. Journal of Essential Oil Research, 18, 189-193. OI:10.1080/10412905.2006.9699063

Teles S, Pereira JA, Santos CH, Menezes RV, Malheiro R, Lucchese AM, Silva F, 2013. Effect of geographical origin on the essential oil content and composition of fresh and dried Menthax villosa Hudson leaves. Industrial Crops and Products, 46, 1-7. doi:10.1016/j.indcrop.2012.12.009

Vokou D, Kokkini S, Bessiere JM, 1993. Geographic variation of Greek oregano (Origanum vulgare ssp. hirtum) essential oils. Biochemical Systematics and Ecology, 21, 287-295. doi:10.1016/0305-1978(93)90047-U 
Table 1. Geographic positions, climatic data, and soil properties of the locations

\begin{tabular}{lcc}
\hline Geographic positions & Andimeshk & Kashkan \\
\hline Altitude $(\mathrm{m})$ & 477 & 1013 \\
Latitude $(\mathrm{N})$ & $32^{\circ} 48^{\prime}$ & $33^{\circ} 35^{\prime}$ \\
Longitude (E) & $48^{\circ} 32^{\prime}$ & $47^{\circ} 53^{\prime}$ \\
\hline Climatic data & & \\
(mean of 10 years 2004-2013) & & \\
\hline Rainfalls $(\mathrm{mm})$ & 371.4 & 376.7 \\
Temperature $\left({ }^{\circ} \mathrm{C}\right)$ & 27.28 & 15.91 \\
Relative humidity $(\%)$ & 32 & 34.7 \\
Evaporation $(\mathrm{mm})$ & 3636.6 & 1890 \\
Sunny hours $(\mathrm{h})$ & 2756 & 2970 \\
\hline Soil properties & & \\
\hline Sand $(\%)$ & 19 & 85 \\
Silt $(\%)$ & 52 & 8 \\
Clay $(\%)$ & 29 & 7 \\
Texture & Silty & Clay Loam \\
EC $\left(\mathrm{ds} / \mathrm{m}^{-1}\right)$ & 4.24 & 0.95 \\
pH & 8.1 & 8.2 \\
Organic carbon $(\%)$ & 0.73 & 0.29 \\
Total N $(\%)$ & 0.07 & 0.03 \\
Available P $\left(\mathrm{mg} \mathrm{kg}^{-1}\right)$ & 5.1 & 13.25 \\
Available K $\left(\mathrm{mg} \mathrm{kg}^{-1}\right)$ & 214 & 157 \\
\hline
\end{tabular}


Table 2. Weather conditions of the locations in the growing season $(2012-2013)$

\begin{tabular}{|c|c|c|c|c|c|c|c|c|}
\hline & \multicolumn{4}{|c|}{ Kashkan location } & \multicolumn{4}{|c|}{ Andimeshk location } \\
\hline \multirow[t]{2}{*}{ Month } & \multicolumn{2}{|c|}{$\begin{array}{l}\text { Monthly rainfall } \\
(\mathrm{mm})\end{array}$} & \multicolumn{2}{|c|}{$\begin{array}{l}\text { Mean monthly } \\
\text { temp. }\left({ }^{\circ} \mathrm{C}\right)\end{array}$} & \multicolumn{2}{|c|}{$\begin{array}{l}\text { Monthly rainfall } \\
(\mathrm{mm})\end{array}$} & \multicolumn{2}{|c|}{$\begin{array}{l}\text { Mean monthly } \\
\text { temp. }\left({ }^{\circ} \mathrm{C}\right)\end{array}$} \\
\hline & 2012 & 2013 & 2012 & 2013 & 2012 & 2013 & 2012 & 2013 \\
\hline April & 9 & 9.9 & 12 & 13.5 & 47.5 & 3.3 & 21.7 & 24.5 \\
\hline May & 11.8 & 91.6 & 18.7 & 15.9 & 5.3 & 143.8 & 30.8 & 25.9 \\
\hline June & 0 & 0.5 & 24.8 & 23.26 & 0 & 0 & 36.7 & 35.2 \\
\hline July & 0 & 0 & 27.9 & 28.3 & 0 & 0 & 39.5 & 39.6 \\
\hline August & 0 & 0 & 29.3 & 26.8 & 0 & 0 & 40.8 & 37.7 \\
\hline September & 0 & 0 & 25.05 & 24.02 & 0 & 0 & 36.3 & 35.9 \\
\hline October & 2.6 & 0 & 20.4 & 17.4 & 1.8 & 0 & 31.4 & 30.2 \\
\hline Mean & 3.34 & 14.5 & 22.59 & 21.31 & 7.8 & 21.01 & 33.88 & 32.7 \\
\hline Total & 23.4 & 102 & 158.15 & 149.18 & 54.6 & 147.1 & 237.2 & 229 \\
\hline
\end{tabular}

Table 3. Time of harvesting (time from transplanting to full flowering) of two species of Satureja (S. khuzistanica and S. reshingeri) in two locations (Andimeshk and Kashkan) in 2012.

\begin{tabular}{lccccc}
\hline & \multicolumn{2}{c}{ Andimeshk } & & \multicolumn{2}{c}{ Kashkan } \\
\cline { 2 - 3 } \cline { 5 - 6 } \cline { 5 - 6 } & S. khuzestanica & S. reshingeri & & S. khuzestanica & S. reshingeri \\
\hline Harvesting & 16 September & 11 October & & 12 October & 160 \\
TTF (day) & 135 & 160 & & &
\end{tabular}

TTF: time from transplanting to full flowering 
Table 4. The effects of species and locations on drug yield, essential oil content, essential oil yield, and plant height (mean of two years).

\begin{tabular}{|c|c|c|c|c|c|c|c|c|c|c|c|c|}
\hline \multirow[t]{2}{*}{ Locations } & \multicolumn{3}{|c|}{ Drug yield $\left(\mathrm{t} \mathrm{ha}^{-1}\right)$} & \multicolumn{3}{|c|}{ Essential oil content (\%) } & \multicolumn{3}{|c|}{ Essential oil yield $\left(\mathrm{kg} \mathrm{ha}^{-1}\right)$} & \multicolumn{3}{|c|}{ Plant height $(\mathrm{cm})$} \\
\hline & $\mathrm{S}_{1}$ & $\mathrm{~S}_{2}$ & Mean $_{L}$ & $\mathrm{~S}_{1}$ & $\mathrm{~S}_{2}$ & Mean $_{L}$ & $\mathrm{~S}_{1}$ & $\mathrm{~S}_{2}$ & Mean $_{L}$ & $\mathrm{~S}_{1}$ & $\mathrm{~S}_{2}$ & Mean $_{L}$ \\
\hline Andimeshk & $1.07 \pm 0.13 \mathrm{c}$ & $1.04 \pm 0.15 \mathrm{c}$ & $1.05 \pm 0.14 \mathrm{~b}$ & $2.1 \pm 0.37 b$ & $4.5 \pm 0.29 a$ & $3.3 \pm 1.2 \mathrm{a}$ & $23.03 \pm 5.4 \mathrm{c}$ & $46.6 \pm 8.06 b$ & $34.8 \pm 13.8 \mathrm{~b}$ & $38 \pm 3.3 b$ & $36.6 \pm 1.7 b$ & $37.3 \pm 2.7 b$ \\
\hline Kashkan & $2.8 \pm 0.31 \mathrm{a}$ & $2.4 \pm 0.37 b$ & $2.6 \pm 0.4 \mathrm{a}$ & $1.8 \pm 0.2 b$ & $4.4 \pm 0.27 \mathrm{a}$ & $3.1 \pm 1.3 b$ & $57.07 \pm 12.04 b$ & $107.9 \pm 16.1 \mathrm{a}$ & $82.5 \pm 29.5 \mathrm{a}$ & $43.1 \pm 2.5 \mathrm{a}$ & $38.6 \pm 4.5 b$ & $40.9 \pm 4.2 \mathrm{a}$ \\
\hline Mean $_{S}$ & $1.9 \pm 0.93 \mathrm{a}$ & $1.7 \pm 0.75 b$ & & $1.9 \pm 0.3 b$ & $4.5 \pm 0.2 \mathrm{a}$ & & $40.05 \pm 19.6 b$ & $77.3 \pm 33.7 \mathrm{a}$ & & $40.5 \pm 3.9 b$ & $37.6 \pm 3.5 b$ & \\
\hline $\mathrm{LSD}_{\mathrm{S}}$ & & & $0.15^{* *}$ & & & $0.2^{* *}$ & & & $6.8^{* * *}$ & & & $2.2^{* * *}$ \\
\hline $\mathrm{LSD}_{\mathrm{L}}$ & & & $0.15^{* *}$ & & & $0.15^{*}$ & & & $6.8^{* *}$ & & & $2.18^{* *}$ \\
\hline $\mathrm{LSD}_{\mathrm{L} \times \mathrm{S}}$ & & & $0.29^{* *}$ & & & $0.32^{\mathrm{ns}}$ & & & $12.31^{* *}$ & & & $3.5^{\mathrm{ns}}$ \\
\hline
\end{tabular}

Drug yield: yield of leaves and flowering shoot; $\mathrm{S}_{1}:$ S. khuzestanica; $\mathrm{S}_{2}$ : S. rechingeri; S: Species; L: Location; L $\times$ S: Location $\times$ Species; NS: not significant;

$* \mathrm{p}<0.05 ; * * \mathrm{p}<0.01$. Values within the same column followed by the same letter are not significantly different $(\mathrm{p} \leq 0.05)$. 
Table 5. Carvacrol content of two species of Satureja (S. khuzistanica and S. reshingeri) in two regions

\begin{tabular}{cccc}
\hline \multicolumn{4}{c}{ Carvacrol content $(\%)$} \\
\hline Locations & S. khuzstanica & S. reshingeri & Mean $_{\mathrm{L}}$ \\
\hline Andimeshk & $95.96 \pm 0.63 \mathrm{a}$ & $95.67 \pm 0.12 \mathrm{a}$ & $95.81 \pm 0.4 \mathrm{a}$ \\
Kashkan & $96.24 \pm 0.06 \mathrm{a}$ & $96.77 \pm 0.07 \mathrm{a}$ & $96.5 \pm 0.3 \mathrm{a}$ \\
Mean $_{\mathrm{S}}$ & $96.1 \pm 0.39 \mathrm{a}$ & $96.22 \pm 0.64 \mathrm{a}$ & \\
\hline LSD $_{\mathrm{L}}$ & $1.15^{\mathrm{ns}}$ & & \\
$\mathrm{LSD}_{\mathrm{S}}$ & $1.1^{\mathrm{ns}}$ & & \\
$\mathrm{LSD}_{\mathrm{LxS}}$ & $0.89^{\mathrm{ns}}$ & & \\
\hline
\end{tabular}

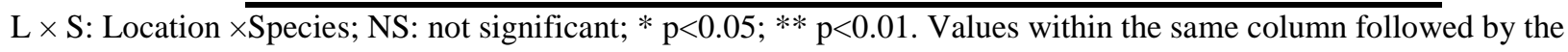
same letter are not significantly different at the $\mathrm{P} \leq 0.05$ level. 

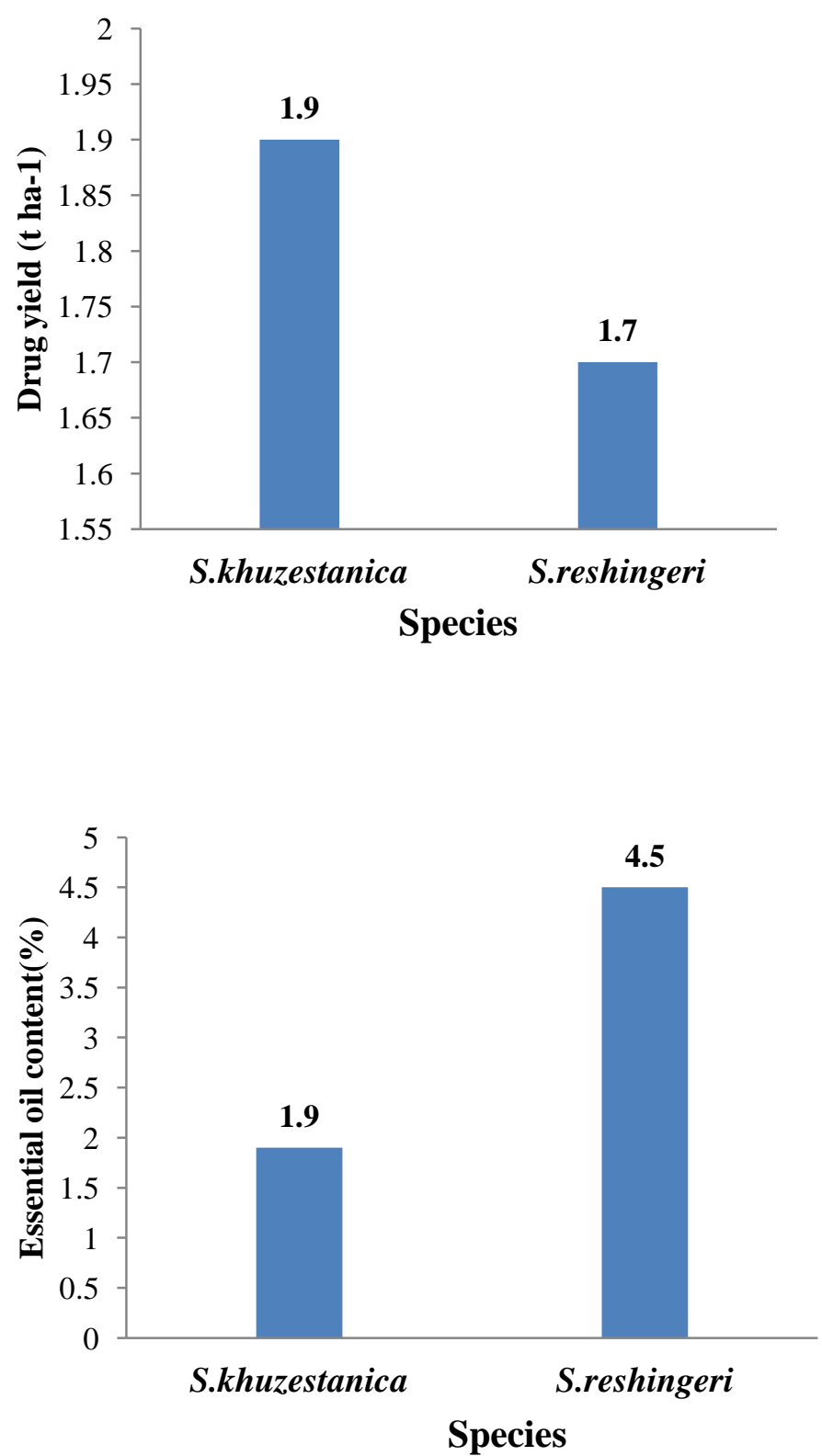

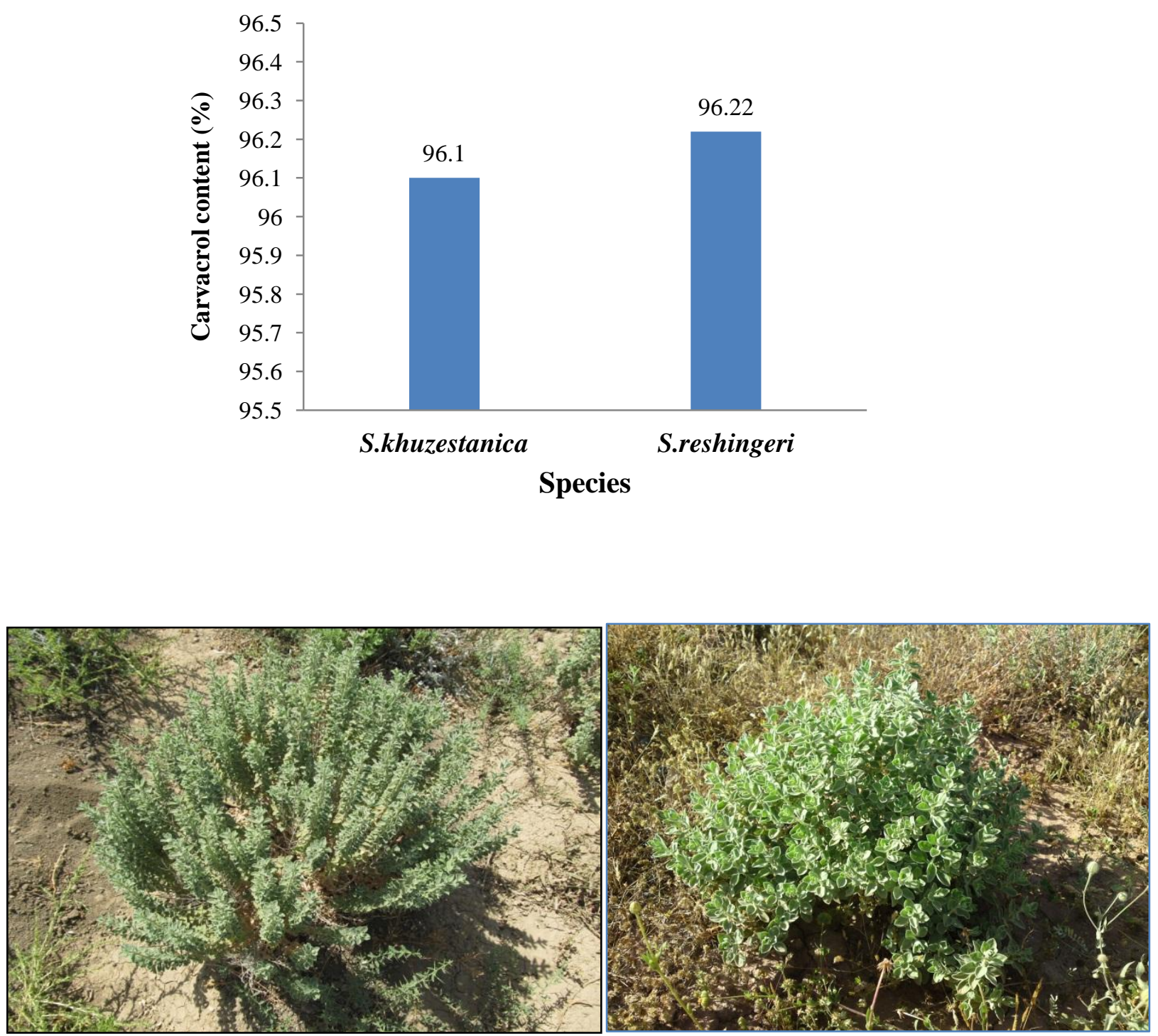

Satureja reshingeri 


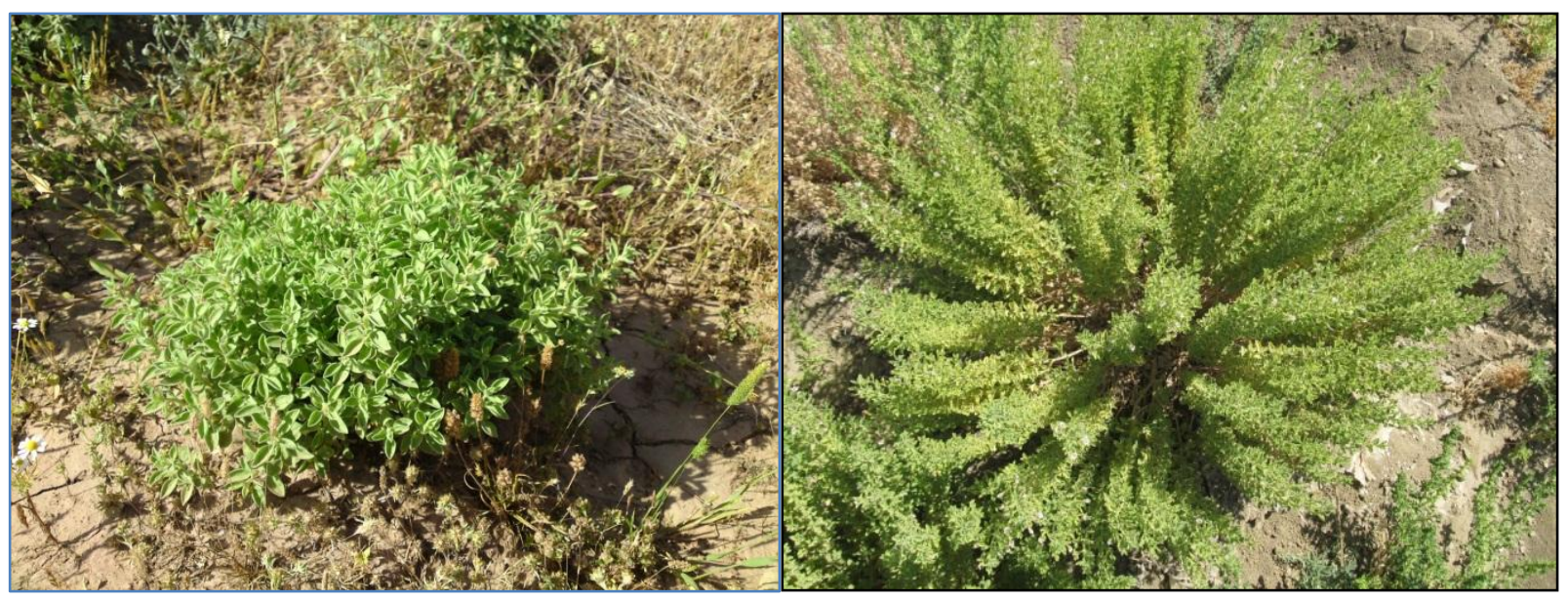

Satureja Khuzestanica 